07

\title{
Органический мемристивный элемент на основе одиночного волокна полианилин/полиамид-6
}

\author{
(C) Д.А. Лапкин ${ }^{1,2}$, С.Н. Малахов ${ }^{1}$, В.А. Демин ${ }^{1,2}$, С.Н. Чвалун ${ }^{1}$ \\ ${ }^{1}$ Национальный исследовательский центр „Курчатовский институт“, \\ Москва \\ ${ }^{2}$ Московский ффизико-технический институт (Государственный \\ университет), Долгопрудный, Московская область \\ E-mail: lapkin@phystech.edu
}

Поступило в Редакцию 24 июля 2017 г.

Получено электропроводящее гибридное волокно на основе полиамида-6, покрытого слоем полианилина, на основе которого собран органический мемристивный элемент. Устройство обладает резистивным переключением с непрерывным характером изменения проводимости. Полученные результаты демонстрируют возможность создания трехмерных стохастических сетей органических мемристивных элементов на основе гибридных нетканых материалов.

DOI: 10.21883/PJTF.2017.24.45337.16982

Мемристоры - элементы, сопротивление которых может быть изменено приложенным напряжением определенной величины (обладающие резистивным переключением), - в настоящее время являются объектом активных исследований как перспективные в качестве элементов памяти. Не менее значимой перспективной областью их применения является разработка нейроморфных систем как материальной основы для аппаратной реализации искусственных нейронных сетей. Это позволит вывести нейросетевую парадигму обработки информации на новый уровень в плане повышения быстродействия и энергоэффективности реализуемых алгоритмов искусственного интеллекта [1].

Достаточно широко изучен эффект резистивного переключения в тонких оксидных пленках, таких как $\mathrm{TiO}_{x}, \mathrm{SiO}_{x}$ и др. [2,3], где предположительным механизмом его возникновения является электромиграция вакансий кислорода, формирующих проводящие области. Особый интерес представляет возможность изготовления мемристивных элементов 
на основе полимерных материалов, основное преимущество которых (наравне с дешевизной и простотой изготовления) - большое число техник обработки, позволяющих формировать как планарные, так и трехмерные структуры $[4,5]$.

Наиболее используемым проводящим электроактивным полимером является полианилин (ПАНИ), различие проводимостей которого в зависимости от редокс-состояния достигает восьми порядков величины, что и обеспечивает функциональность мемристивного элемента на его основе. В качестве противоэлектрода при окислительно-восстановительной реакции, в ходе которой происходит обратимое изменение состояния ПАНИ, используется серебряная проволока. Средой для данной реакции служит твердый электролит-полиэтиленоксид (ПЭО), легированный перхлоратом лития. Была показана возможность изготовления такого элемента простым и масштабируемым методом спинкоатинга [6].

Перспективным направлением исследований является изготовление стохастических сетей органических мемристивных элементов на трехмерных волокнистых матрицах, содержащих ПАНИ. Один из способов создания таких матриц - синтез ПАНИ на нетканых полимерных материалах, получаемых методом электроформования. Электроформование - процесс вытягивания полимерных микро- и нановолокон из растворов или расплавов полимеров электрическим полем, который позволяет получать трехмерные волокнистые матрицы с регулируемыми характеристиками (диаметр волокон, поверхностная плотность, пористость и т.д.) из широкого ряда полимеров.

При создании стохастической сети мемристивных элементов на основе такого трехмерного нетканого материала принципиально важным является качество его сопряжения с электродами и полиэлектролитным слоем. Для демонстрации принципиальной возможности изготовления такой стохастической сети в настоящей работе мемристивный элемент собирали на основе одиночного волокна, на котором был синтезирован слой ПАНИ. Нетканый материал получался электроформованием расплава полиамида-6 (ПА-6) марки Волгамид-27 (КуйбышевАзот, относительная вязкость 2.7) при температуре $300^{\circ} \mathrm{C}$ и напряжении $135 \mathrm{kV}$ (схема установки и подробное описание процесса представлены в [7]). После этого из материала извлекались одиночные волокна диаметром 100-200 $\mu \mathrm{m}$, которые закреплялись в стеклянном держателе, погружались в раствор $0.2 \mathrm{M}$ гидрохлорида анилина (Acros

Письма в ЖТФ, 2017, том 43, вып. 24 
Organics, 99\%) в $1 \mathrm{M}$ растворе соляной кислоты и выдерживались при комнатной температуре для адсорбции анилина на поверхность волокон. Через час в реакционную смесь доливался инициатор полимеризации - раствор персульфата аммония (Acros Organics, $98+\%$ ) - до достижения эквимолярной концентрации с анилином. Полимеризация проводилась в течение $2 \mathrm{~h}$ при комнатной температуре, после чего волокна извлекались, промывались в $0.1 \mathrm{M}$ растворе соляной кислоты и сушились в течение $24 \mathrm{~h}$.

Толщина полученного слоя ПАНИ на поверхности волокон по данным оптической микроскопии составила около $1 \mu \mathrm{m}$. Удельная проводимость с учетом полученной толщины превысила $1 \mathrm{~S} / \mathrm{cm}$, что является хорошим показателем для данного проводящего полимера.

Сборка мемристивного элемента проводилась на стеклянной подложке, на которую магнетронным напылением предварительно были нанесены два титановых электрода с расстоянием между ними $7 \mathrm{~mm}$. В зазоре, по центру между электродами, помещалась серебряная проволока диаметром $50 \mu \mathrm{m}$, на которую, избегая контакта с электродами подложки, наносили раствор ПЭО (30 g/l) в $0.1 \mathrm{M}$ растворе перхлората лития. После высыхания первого слоя, предотвращающего контакт серебряной проволоки с проводящим волокном, наносился второй слой, на который помещалось полученное гибридное волокно ПАНИ/ПА-6 в направлении, перпендикулярном серебряной проволоке. Концы проводящего волокна фиксировались на электродах подложки электропроводящим клеем „Контактол“ на основе серебра. Полученный элемент высушивался в потоке воздуха. Схематичное изображение такого мемристивного элемента представлено на рис. 1.

Электрофизические характеристики мемристивного элемента были определены посредством системы измерения характеристик полупроводников Keithley4200-SCS. Для характеризации такого элемента один из электродов подложки (по аналогии с полевыми транзисторами „сток“) и серебряная проволока („затвор“) заземлялись, на оставшийся электрод подложки („исток“) подавалось напряжение $V$. Измерялись полный ток $I_{s}$, текущий через элемент (ток истока), и ток $I_{g}$, текущий через серебряную проволоку (ток затвора), возникающий при окислительно-восстановительной реакции на границе раздела ПАНИ и ПЭО. Сканирование напряжения проводилось с шагом $0.1 \mathrm{~V}$ в пределах значений от -0.6 до $+1 \mathrm{~V}$, которые выбраны таковыми во избежание необратимого переокисления ПАНИ при потенциалах выше $+1 \mathrm{~V}$ и

Письма в ЖТФ, 2017, том 43, вып. 24 


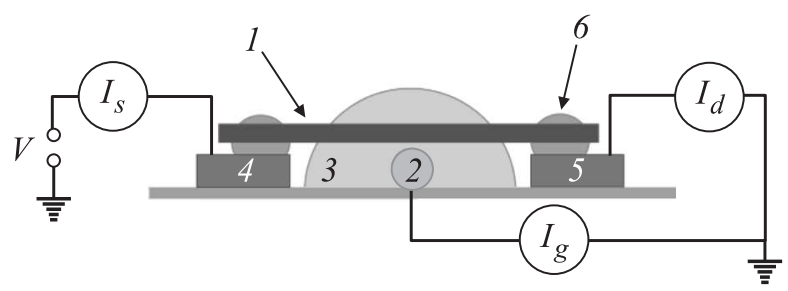

Рис. 1. Схема сборки и характеризации мемристивного элемента на основе гибридного волокна ПАНИ/ПА-6: 1 - гибридное волокно ПАНИ/ПА-6, 2 - серебряная проволока (затвор), 3 - твердый электролит, 4 и 5 - электроды подложки (исток и сток соответственно), 6 - электропроводящий клей.

гидролиза остаточной воды в слое ПЭО. Ток фиксировали через $1 \mathrm{~min}$ после подачи напряжения для протекания электрохимической реакции. Полученные таким образом вольт-амперные характеристики (BAX) для полного тока и тока затвора приведены на рис. 2.

При сканировании напряжения от 0 до $+0.4 \mathrm{~V}$ проводимость элемента остается стабильно низкой. При дальнейшем увеличении напряжения начинается рост тока затвора, который достигает максимума при напряжении $+0.6 \mathrm{~V}$, при котором начинается резкий рост полного тока, текущего через элемент, что свидетельствует об окислении слоя ПАНИ на поверхности волокна и переходе элемента в высокопроводящее состояние. При дальнейшем сканировании напряжения проводимость элемента остается высокой до достижения при снижении напряжения значения $+0.2 \mathrm{~V}$, при котором наблюдается отрицательный пик тока затвора и резкое падение полного тока, что указывает на восстановление ПАНИ и переход элемента в низкопроводящее состояние. Таким образом, характерными напряжениями переключения мемристивного элемента являются +0.2 и $+0.6 \mathrm{~V}$ для переключения в низкопроводящее и высокопроводящее состояния соответственно, между ними $(0.3-0.4 \mathrm{~V})$ проводимость элемента остается довольно стабильной, что и позволяет говорить о наличии у такого элемента мемристивных свойств.

Для изучения процесса резистивного переключения были измерены временнб́е зависимости проводимости при приложении напряжений, при которых происходит окисление ПАНИ-канала и его восстановление, что приводит к увеличению и снижению проводимости мемристивного элемента соответственно. С учетом характерных величин 


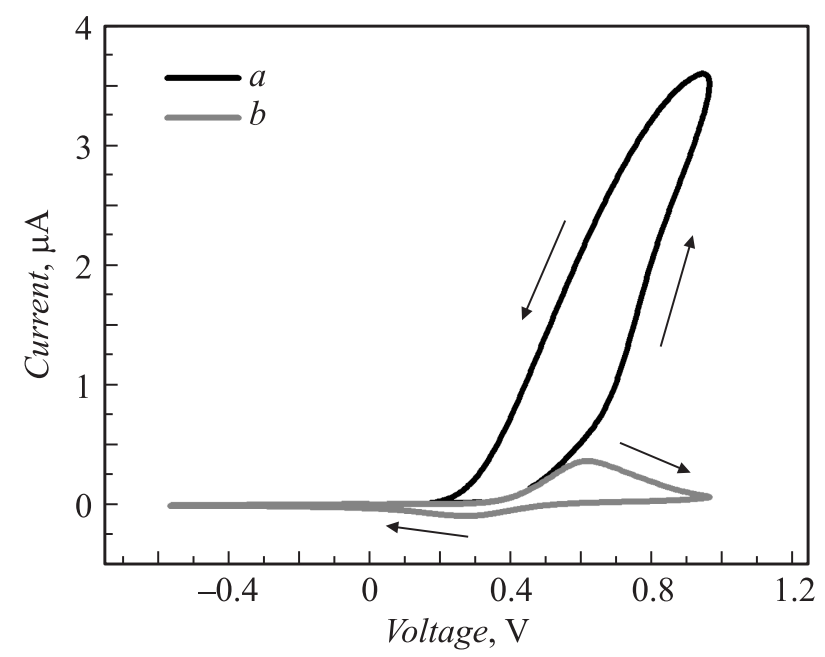

Рис. 2. BAX мемристивного элемента на основе гибридного волокна ПАНИ/ПА-6: полный ток $(a)$ и ток затвора $(b)$, стрелки указывают направление сканирования напряжения.

напряжений, полученных при исследовании ВАХ элемента, были выбраны напряжения $+0.8 \mathrm{~V}$ для перевода элемента в высокопроводящее состояние (потенциации) и $-0.3, \mathrm{~V}$ для перевода в низкопроводящее состояние (депрессирования). Полученные таким образом временны́е зависимости представлены на рис. 3.

Видно, что переход в низкопроводящее состояние происходит значительно быстрее, чем переход в высокопроводящее состояние. Возможной причиной такого поведения является распределение потенциала в месте контакта ПАНИ и ПЭО. Так, при подаче положительного напряжения лишь часть волокна, контактирующего с ПЭО, имеет потенциал выше значения $+0.5 \mathrm{~V}$, при котором происходит его окисление, что приводит к постепенному распространению окисленной области от истока к стоку элемента и медленному изменению его проводимости. При подаче же отрицательного напряжения все волокно имеет потенциал ниже значения $+0.2 \mathrm{~V}$, при котором происходит его восстановление, что вызывает резкое падение проводимости элемента. Данные результаты находятся в качественном соответствии с электрохимической моделью 


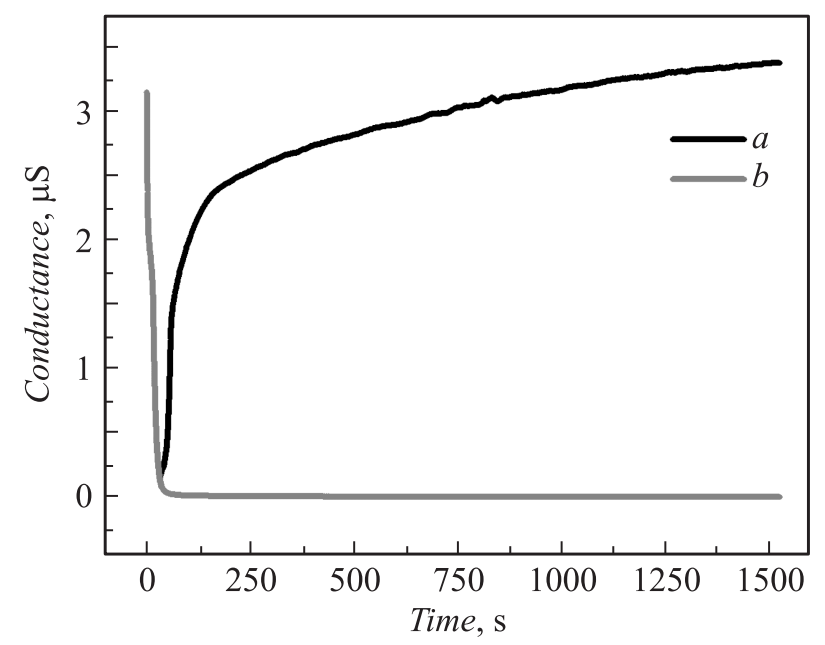

Рис. 3. Кинетика изменения проводимости мемристивного элемента на основе гибридного волокна ПАНИ/ПА-6 при подаче напряжений, повышающих $(+0.8 \mathrm{~V})(a)$ и понижающих $(-0.3 \mathrm{~V})(b)$ проводимость.

переключения, разработанной для тонкопленочных мемристивных элементов на основе ПАНИ [8].

Кроме того, изменение проводимости носит непрерывный характер, что позволяет использовать не только крайние состояния проводимости элемента, но и любые промежуточные, что принципиально важно для реализации аналоговых искусственных нейронных сетей на основе таких мемристивных элементов, где проводимость играет роль весового коэффициента связи между „нейронами“. Кинетические зависимости проводимости могут быть аппроксимированы экспоненциальными зависимостями с характерными временами 51 и $14 \mathrm{~s}$ для потенциации и депрессирования соответственно. Эти значения приближаются к характерным временам переключения лучших образцов традиционных планарных мемристивных элементов на основе ПАНИ, полученных методом Ленгмюра-Шеффера [9].

Таким образом, на примере сборки органического мемристивного элемента на базе одиночного гибридного волокна ПАНИ/ПА-6 показана перспективная возможность использования трехмерных нетканых материалов ПАНИ/ПА-6 для создания стохастических сетей мемристивных

Письма в ЖТФ, 2017, том 43, вып. 24 
элементов на их основе, что позволит единовременно получать нейроморфные системы, способные к обучению решению сложных линейно неразделимых задач.

Работа выполнена при частичной финансовой поддержке гранта Президента РФ для государственной поддержки молодых российских ученых-кандидатов наук (МК-2757.2017.3) и РФФИ (проект № 15-29-01324 офи_м) с использованием оборудования ресурсных центров (ЭФМ, ОМС) НИЦ „Курчатовский институт“.

\section{Список литературы}

[1] Демин В.А., Емельянов А.В., Лапкин Д.А. и др. // Кристаллография. 2016. T. 61. № 12. C. 958-968.

[2] Храповищкая Ю.В., Маслова Н.Е., Грищенко Ю.В. и др. // Письма в ЖТФ. 2014. T. 40. B. 7. C. $87-94$.

[3] Белов А.И., Михайлов А.Н., Королев Д.С. и др. // Письма в ЖТФ. 2016. Т. 42. B. 10. C. 17-24.

[4] Das B.C., Pillai R.G., Wu Y. et al. // ACS Appl. Mater. Inter. 2013. V. 5. P. $11052-$ 11058.

[5] Erokhin V., Berzina T., Gorshkov K. et al. // J. Mater. Chem. 2012. V. 22. P. 22881-22887.

[6] Lapkin D.A., Korovin A.N., Demin V.A. et al. // BioNanoScience. 2015. V. 3. P. 181-184.

[7] Малахов С.Н., Белоусов С.И., Щербина М.А. и др. // Высокомолекуляр. соединения А. 2016. Т. 58. № 2. С. 169-178.

[8] Demin V.A., Erokhin V.V., Kashkarov P.K. et al. // J. Appl. Phys. 2014. V. 116. P. 064507.

[9] Emelyanov A.V., Lapkin D.A., Demin V.A. et al. // AIP Adv. 2016. V. 6. P. 111301. 